KES-SDM 2019. Smart Innovation, Systems and Technologies,

Proceedings of the 6th International Conference on Sustainable Design and Manufacturing,

4-5 July 2019, Budapest, Hungary. Volume 155, pp. 283-297

DOI: 10.1007/978-981-13-9271-9_24

\title{
Life Cycle Assessment of Graphene as Heating Element
}

\author{
Araba Darkoa Ampah, Emanuele Pagone, Konstantinos Salonitis \\ Sustainable Manufacturing Sy stems Centre, Cranfield University, Cranfield, Bedfordshire, \\ M K43 0AL, United Kingdom \\ e.pagone@cranfield.ac.uk | k.salonitis@cranfield.ac.uk
}

\begin{abstract}
Among the various applications of graphene is the heating purpose due to its promising thermal conductivity. This paper presents a life cycle model of graphene, capturing the "cradle to gate" approach, focusing on energy consumption and environmental impact of graphene. The embodied energy consumption was calculated based on empirical data in scientific papers, patents and databases while life cycle assessment modelling software was utilised for analysing its environmental impact. The result from the analysis shows that, the embodied energy for the synthesis of $1 \mathrm{~kg}$ of graphene ranges between 264-304 MJ. Further analysis shows that, $42 \%$ of graphene embodied energy is consumed from powder preparation through to graphitization process. Moreover, the result obtained from the modelling shows dust particles and $\mathrm{CO}_{2}$ emissions into air during graphene production. This paper should be followed by further study on graphene use and end of life phases to establish a comparison with the traditional heating materials.
\end{abstract}

\section{Introduction}

Graphene, a two-dimensional honeycomb carbon lattice, has drawn attention of research focus on multitude of different graphene related areas including graphene as heating elements [1-3] as energy storage [4], as semiconductor [5], as structural reinforcement [6] and as membrane for liquids [7] or gas [8] separation. Graphene firstly obtained in 2004 using sticky tape on graphite (micromechanical cleavage) and reported to have thermal and electronic properties [9] is a promising material to replace several materials commonly used in today's devices in the future. Life cycle assessment (LCA) is defined in the 14040 ISO standards as a way of addressing the environmental impacts (resource use and its effects on the environment) of a product's life cycle from the acquisition of raw materials through production, use and end of life (recycling and or final disposal, i.e. "cradle to grave"). The "cradle to grave" approach, as represented in Fig. 1, includes the energy utilisation that occurs during resource extraction and processing, production, use, and end of life processing of graphene. This holistic and comprehensive approach aims at avoiding shifting environmental burdens from one stage of the life cycle to another and a complete picture of graphene properties can be ascertained. 


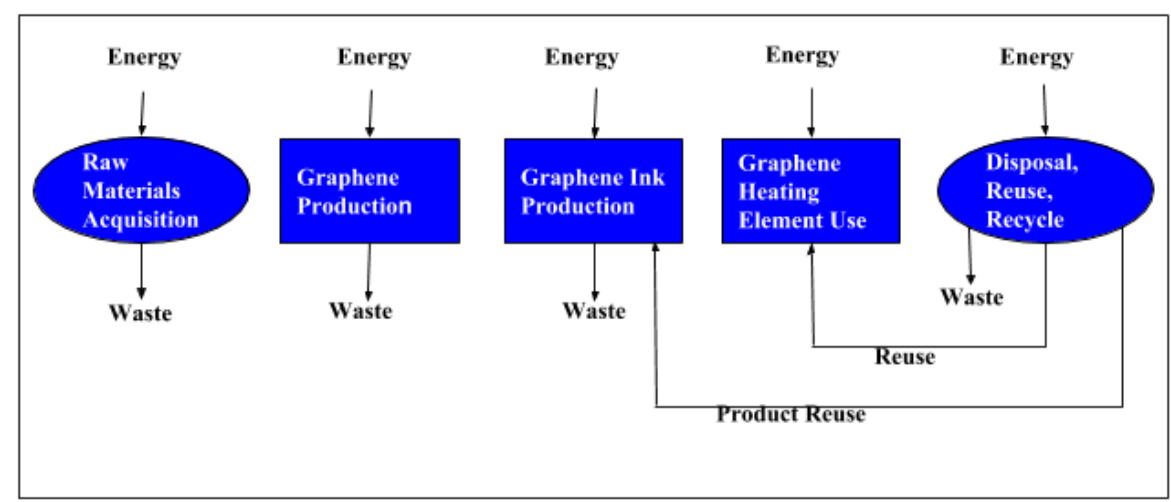

Fig. 1. Representation of the "cradle to grave" approach of graphene product life cycle. Adapted and modified [10].

Recent research publications on the numerous applications of graphene, due to it $s$ mechanical, thermal and electronic properties have led to several concerns over the economic and environmental burdens that this material might have on the society [11]. There is the need for investigation on the economic and or environmental burdens as associated with a product or system when produced in commercial scale thus, to put down measures to reduce or avert these burdens that may occur before the full development of the product or system. Graphene with very high thermal conductivity above $3000 \mathrm{~W} /(\mathrm{m} \mathrm{K})$ [12] and able to withstand extremely high densities of electric current (a million times higher than copper) [13] is possible to be highly suitable as heating element. The high thermal conductivity property indicates that, it can outperform carbon nanotubes regarding heat conduction [14]. With the threat of global warming and climate change, technological advancement is no longer the only priority as there is now a necessity of abating the environmental impacts and risks associated with emerging technologies. Also, the LCA approach avoids shifting the environmental burden from one impact category to another [11]. These necessitated a comprehensive study to investigate the energy consumption of graphene hence, the application of LCA technique.

This paper aims to institute a life cycle model of graphene, capturing the "cradle to gate" approach. The paper focuses on the energy consumption and overview of environmental impact associated with industrial production of graphene as heating element.

\section{Graphene Production}

Graphene is produced primarily from graphite, either Highly Oriented Pyrolytic Graphite (HOPG-artificial) or graphite flakes (natural) [9,15]. HOPG production processing which was invented and firstly produced by E. G. Acheson in 1896 [16] is made up of filler and binder components. The filler constituting over $80 \%$ of total raw materials mass [17] is normally chosen from carbon materials that graphitise readily 
whereas the binder, usually coal-tar pitch represents about $15-30 \%$ of the total material mass [18].

A loss of $25 \%$ carbon is assumed after the graphitization process for every $1 \mathrm{~kg}$ of graphite with density range of $2.1-2.3 \mathrm{~g} / \mathrm{cm}$ when produced [18]. Based on the volatile mass loss and the ratio of filler to binder, it can be deduced that, for every $1 \mathrm{~kg}$ of graphite produced requires about $1.25 \mathrm{~kg}$ raw materials of which $80 \%$ is coke and $20 \%$ pitch. Graphene production methodologies can be classified into; exfoliation (dry, liquid phase (LPE) [19], and electrochemical exfoliation (EE) [20], chemical and thermal routes and Chemical Vapour Deposition (CVD).

\subsection{Graphene as Heating Eement}

Graphene ink can be used for heating element as in the case of conventional heating systems made from copper or alloy. It is reported that, the commercial film-like heater made from strips of a $\mathrm{Fe}-\mathrm{Cr}-\mathrm{Al}-\mathrm{b} a s e d$ alloy has many disadvantages including complicated fabrication process, opacity, heavy weight, rigidity, and low heating efficiency [1-3]. Possibly, graphene ink can be used to replace the conventional heating elements due to its various properties including thermal, conductive, light weight, flexible among others.

a

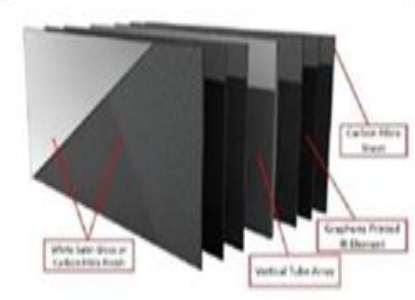

c

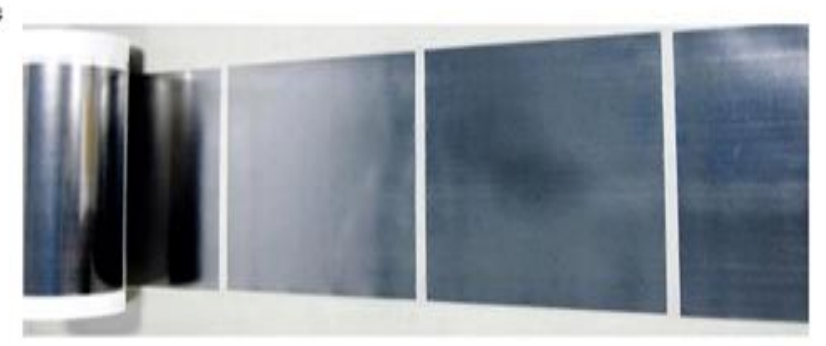

b

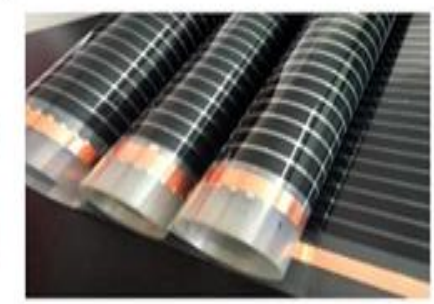

Fig. 2. Graphene heating elements: (a) Graphene radiator, (b) and (c) Forms of graphene underfloor heating element.

Graphene Ink. Zaier et al documented that, the coating strategy of graphene ink works with a variety of substrates (textile, paper, glass, wood, plastic and stainless steel) [21]. Possible graphene ink can be applied on board (plastic, wood or stainless 
steel) to replace the existing heating elements as shown in Fig. 2, due to its conductive property [22]. High conductivity of graphene permits electrons to travel about onethird of the speed of light and, its low thermal mass [23,24] expedient heating (instant) without wastage of energy heating up the heater itself.

Graphene Ink Production. The production of graphene ink requires basic elements comprising of conductive or functional material, binder and carrier $[25,26]$. The functional material, normally an electrically conductive form of carbon such as graphite, carbon black or activated carbon powder should be at least $30 \%$ of the wet weight of the ink [25]. The binder holds the conductive material (graphene) together while allowing to flex. [25] further documented that, the preferred binder's dry weight should range from $3 \%$ to $5.18 \%$ by of the wet weight of the composition and the binder, usually used in a solution in water. The composition should be about 30-50\% of wet weight of the binder solution [25] which can be deduced that; the dry binder and water ratio should be approximately 1:10 respectively. A conductive graphene ink can be produced by dispersing exfoliated graphite (EG) flakes in DMF [27] with a high concentration $(10 \mathrm{mg} / \mathrm{mL})$ followed by sonication [27,28] for 20 minutes [27]. This method of graphene ink production seems promising for industrial scale since the sonication process promotes quick and even dispersion of graphene in the solution compared to the stirring method employed by Murray-Smith [26]. The weight of graphene in the ink contributes to the properties of the ink and its application. Ink for heating purpose may have high concentration of graphene due to the thermal, conductive and transfer of heating properties required for such application.

\subsection{Environmental Impact of Graphene Production}

Nanosafety which can be defined as all the safety issues related to nanotechnology, is required to interpret any future development of new nanotechnologies into action, from commercial applications to health care approaches [29, 30]. Graphene Related Materials (GRMs) are possible to have risks on health or environment as shown in Fig. 3. It is essential to discover the level of toxicity and to establish, if required, constraints for safety of use [31-36].

\section{$3 \quad$ Methodology}

The approach adopted in obtaining the results is graphically represented in Fig. 4.

\subsection{Process Mapping}

The project first saw the process mapping of graphene using flowcharts to capture relevant processes from its feedstock through to graphene ink production. After which IDEF0 was used to further develop the map to capture the necessary production details including inputs, outputs, temperature, equipment, process time as indicated in Fig. 5. 


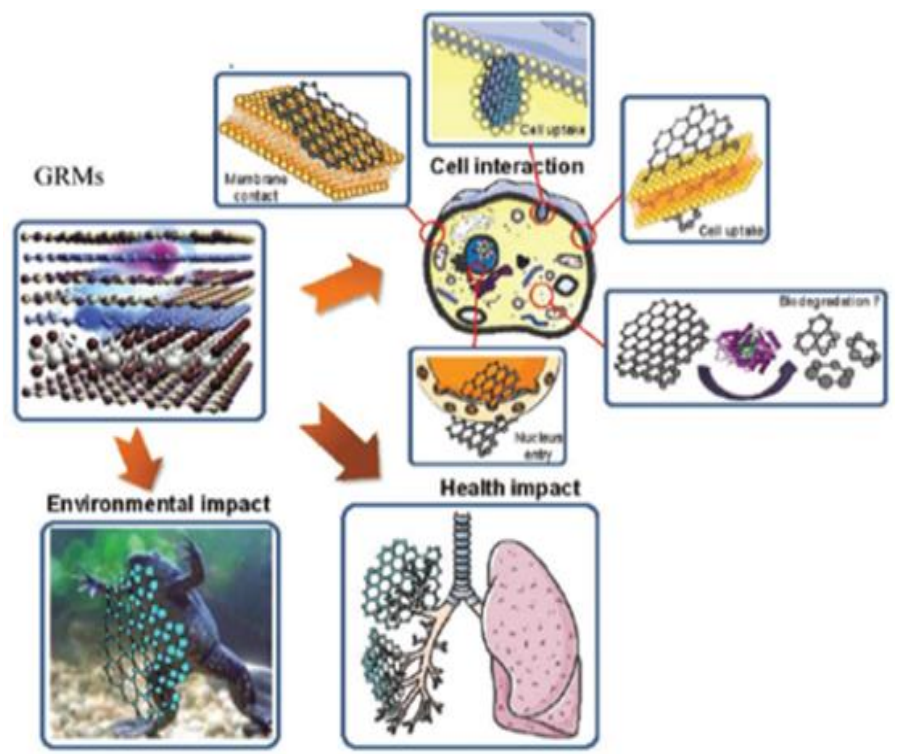

Fig. 3. Possible interactions of Graphene Related Materials (GRMs) with cells, organs (i.e. lung) and living organisms (i.e. amphibian) [36].

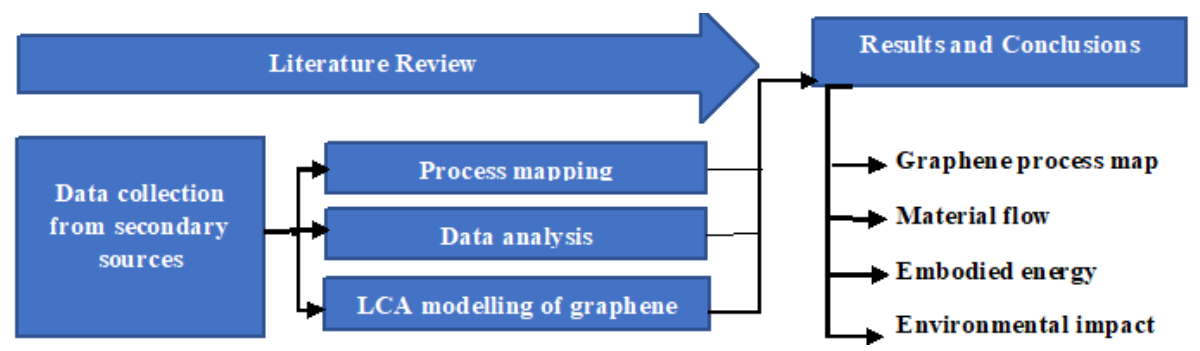

Fig. 4. High level approach adopted in obtaining research results.

Raw Materials Energy Calculation. To calculate the HOPG energy, 80:20\% representing coke and pitch quantity flow was applied [17,18]. Their equivalent production embodied energy quoted in [37] served as foundation to the energy calculation of graphene ink production. About $1.25 \mathrm{~kg}$ of both coke and pitch was used to calculate the production of $1 \mathrm{~kg}$ of HOPG. To obtain graphene processing energy, the contribution of coke and pitch embodied energy was subtracted from the graphite embodied energy.

The primary production (energy and $\mathrm{CO}_{2}$ ) and material processing (energy and $\mathrm{CO}_{2}$ ) was added to obtain graphite embodied energy. The quantity of $\mathrm{H}_{2} \mathrm{SO}_{4}$ used in the analysis was derived from the graphite to solution ratio quoted in [38]. 


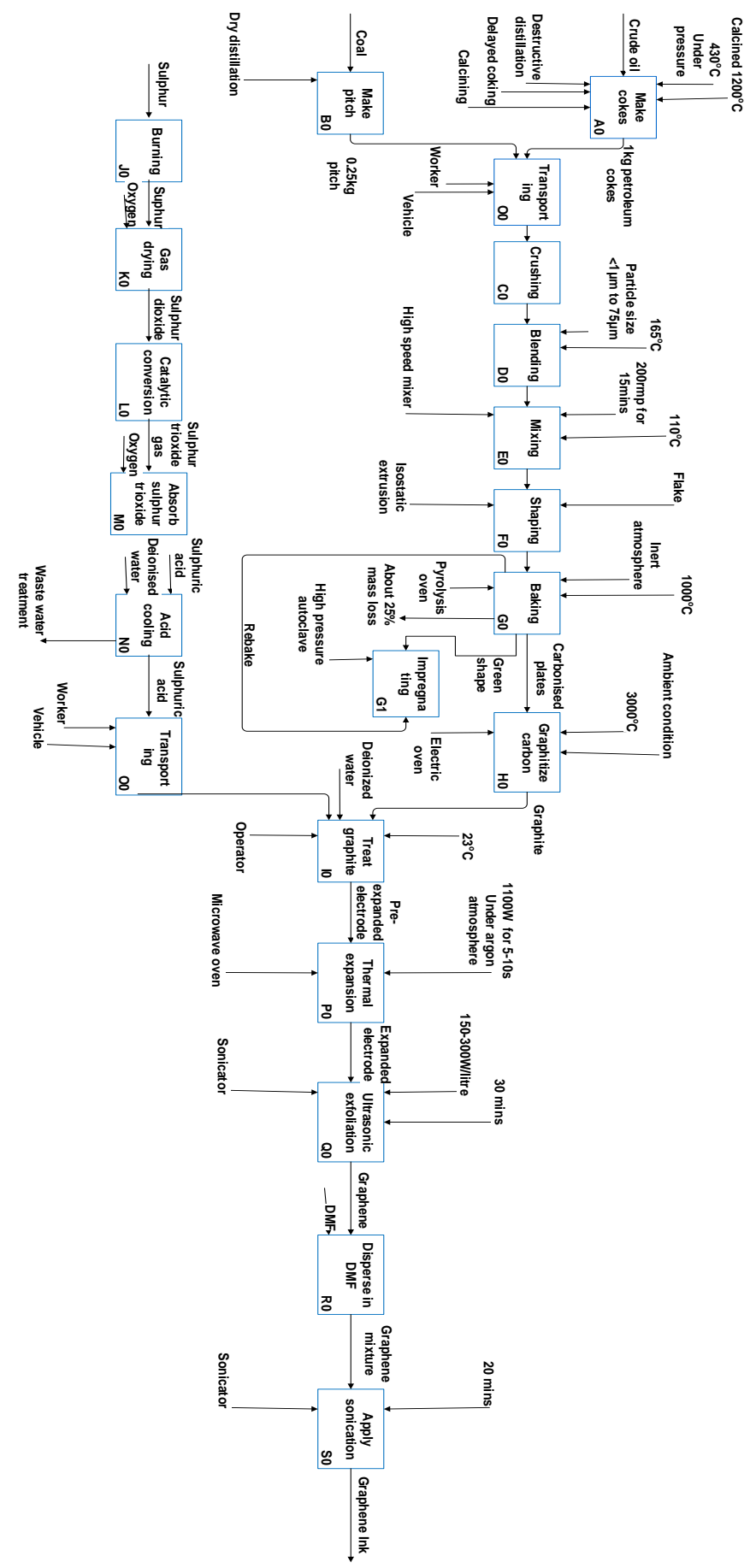

Fig. 5. Graphene process map capturing the "cradle to gate" approach 
Production Processes Energy Calculation. The energy requirement at the pretreatment of graphene was calculated based on the embodied energy of sulphuric acid quoted in [39]. Microwave expansion energy was obtained using a power of $1100 \mathrm{~W}$ [38] for a time of 5-10 s [20]. 150-300 W per litre solvent for 30 minutes [47] was applied for the ultrasonic exfoliation energy calculation. The process energy is calculated assuming a constant power level for the time required by the process. The results from all the processing energy were added to the raw materials energy to derive graphene embodied energy result.

Graphene Ink Energy Calculation. The ratio 30:70\% of graphene to Dimethylformamide (DMF) respectively [25] was used in the ink energy calculation. The Cumulative Energy Demand (CED) for $1 \mathrm{~kg}$ of DMF recorded in [41] was applied. The sonication process energy was calculated based on the power reference quoted by [40] with process duration recorded by [27]. The energy and materials mass flow for graphene ink production are graphically represented via Sankey diagram.

\subsection{Environmental Impact}

GaBi software was used in modelling the LCA of graphene production. The modelling captures the high-level production processes of graphene from it feedstock through to graphene ink production. Most of the data fed into the system were identified and retrieved from $\mathrm{GaBi}$ database with few entered manually from the results of the analysis. Data fed into the system was then analysed by GaBi software to obtain the environmental impact results of graphene production.

\section{Results}

\subsection{Graphene Process Map}

From a high-level point of view, a graphene process map is represented by Fig. 5 and comprises three major steps: graphite production, graphene production and graphene ink production. These processes represent raw materials acquisition, graphene production and graphene use phase in Fig. 1 respectively. The temperatures, pressure, time, equipment and inputs contribute to the energy consumption at each process as indicated in Fig. 1 and the waste is denoted by the losses that flow out of the processes. Fig. 5 shows that graphite production demands the production of both coke and pitch which is captured as 'make petroleum coke' and 'make pitch' respectively. The first production process after transportation is the powder preparation which begins with crushing of the raw materials through to the mixing to obtain an even mixture. The powder preparation occurs below $200^{\circ} \mathrm{C}$ followed by shaping the mixture, referred to the output as 'green shape'. The baking process occurs in high temperature of about $1000^{\circ} \mathrm{C}$ in inert atmosphere and this leads to volatile mass loss when temperature is about $300-550^{\circ} \mathrm{C}$. The mass loss estimated to be about $25 \%$ of the total mass of the coke and pitch mixture occurs at this stage. The carbonised material is impregnated 
with coal tar and baked again before the next stage. Graphitization, the final process of graphite production, is

very significant because at this stage, the carbonised material is transformed into graphite. Graphitization process uses high temperatures, up to $3000^{\circ} \mathrm{C}$, which is 3 times higher than the baking temperature.

\subsection{Materials Flow}

The flow of materials or processes associated with graphene ink production is graphically shown as Fig. 6. It has three main subdivisions including inputs (materials on the left-hand sides), processes (grouped in the middle of the flow) and outputs (materials at the right). Fig 6 shows that some output like graphite and graphene serve as input to pre-treatment and sonication respectively. Water represents the high flow of $20 \mathrm{~kg}$, followed by DMF of $2.2 \mathrm{~kg}$. Unexfoliated graphite represents the low flow of about $0.05 \mathrm{~kg}$ out of $3.2 \mathrm{~kg}$ of graphene ink. Fig 6 indicates that, 95\% of the HOPG is exfoliated into graphene $(0.95 \mathrm{~kg})$ indicating high efficiency of the process.

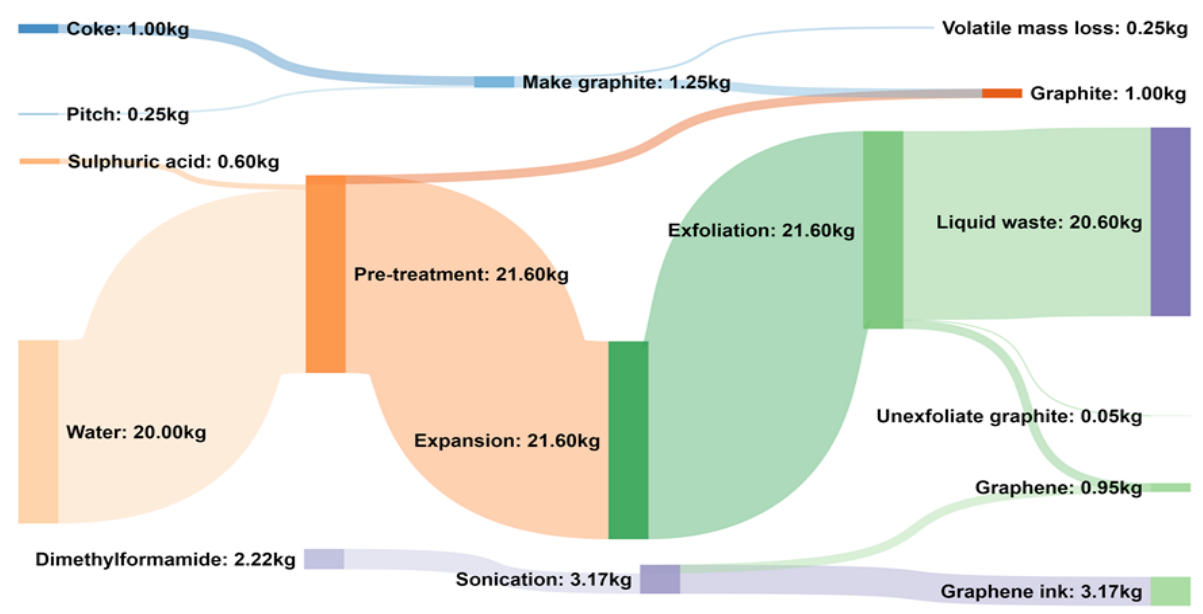

Fig. 6. Mass flow of processes or materials to produce about $3.2 \mathrm{~kg}$ of graphene ink

Unexfoliated graphite, $0.05 \mathrm{~kg}$ accounts for a loss of $5 \%$ (maximum) for every 1 $\mathrm{kg}$ of graphite used which depicts less energy wastage under the material flow. The use of 30:70\% ratio of HOPG to DMF respectively results in ink of high level graphene concentration required to possess thermal and conductive properties needed for heating purposes.

\subsection{Estimated Embodied Energy}

Graphite, the primary raw material for graphene production requires about 237-260 MJ for every $1 \mathrm{~kg}$ produced. Table 1 shows the energy consumption of graphite production accounting for embodied energy of $1 \mathrm{~kg}$ of petroleum coke and $0.25 \mathrm{~kg}$ of 
coal tar pitch as 31-35 MJ and 90-103 MJ respectively. The production processes including powder preparation, baking, impregnation and graphitization requires about 114-123 MJ of energy for every $1 \mathrm{~kg}$ of graphite produced and is captioned as 'make graphite' in Tab. 1.

Table 1. Estimated embodied energy for the synthesis of $1 \mathrm{~kg}$ of HOPG

\begin{tabular}{lcc}
\hline Process/Material & Quantity $(\mathrm{kg})$ & Embodied Energy $(\mathrm{MJ})$ \\
\hline Petroleum coke & 1 & $31.94-35.17$ \\
Resin impregnated carbon & 0.25 & $90.23-102.64$ \\
Make graphite & 1.25 & $114.35-122.6$ \\
Graphite & 1 & $236.52-260.41$ \\
\hline
\end{tabular}

From Tab. 2, the embodied energy to produce about $0.95 \mathrm{Kg}$ of graphene is estimated to range between 252-290 MJ. This accounts for the energy consumption for the production of sulphuric acid at pre-treatment (1.19 MJ), expansion (7.92-15.84 MJ) and ultrasonic exfoliation (5.83-11.66 MJ) processes as shown in Tab. 2.

Table 2. The embodied energy to produce about $0.95 \mathrm{~kg}$ of graphene

\begin{tabular}{lll}
\hline Process/Material & Quantity $(\mathrm{kg})$ & Embodied Energy $(\mathrm{MJ})$ \\
\hline Graphite & 1 & $236.52-260.41$ \\
Pre-treatment & 0.6 & 1.19 \\
Microwave expansion & 21.6 & $7.92-15.84$ \\
Ultrasonic exfoliation & 21.6 & $5.83-11.66$ \\
\hline
\end{tabular}

The energy to produce $20 \mathrm{~kg}$ of water used in the pre-treatment process is captured under miscellaneous in Fig. 8. Further analysis indicates that, the estimated energy to produce $1 \mathrm{~kg}$ of graphene ranging between 264-304 MJ is higher compared to $141-157 \mathrm{MJ}$ of energy consumed for every $1 \mathrm{~kg}$ of copper produced [37]. This implies that, for every $1 \mathrm{~kg}$ of graphene produced requires about $90 \%$ more energy than $1 \mathrm{~kg}$ of copper produced.

Tab. 3 shows that, for every $3.2 \mathrm{~kg}$ of graphene ink produced consumes about 454-492 MJ of energy. This includes the energy usage for graphene production (251$289 \mathrm{MJ}), \mathrm{DMF}(202 \mathrm{MJ})$ and the sonication process (0.57-1.14 MJ). Further analysis shows that, for every $1 \mathrm{~kg}$ of graphene ink produced, about 142-154 MJ of energy is consumed. This implies that, for every $1 \mathrm{~kg}$ of graphene produced uses $52 \%$ more energy than for every $1 \mathrm{~kg}$ of graphene ink produced. 
Table 3. The embodied energy to produce about $3.2 \mathrm{~kg}$ of graphene ink

\begin{tabular}{lcl}
\hline Process/Material & Quantity $(\mathrm{kg})$ & Embodied Energy $(\mathrm{MJ})$ \\
\hline Graphene & 0.95 & $251.46-289.1$ \\
DMF & 2.22 & 201.97 \\
Sonication & 3.17 & $0.57-1.14$ \\
Graphene ink & 3.17 & $454-492.21$ \\
\hline
\end{tabular}

\subsection{Energy Flow}

Fig. 7 shows the flow of energy for graphene ink production. The dispersion process accounts for the high energy consumption representing about $202 \mathrm{MJ}$ out of the average 473 MJ required for the graphene ink production. Next to dispersion is make graphite representing $119 \mathrm{MJ}$ followed by pitch, $94 \mathrm{MJ}$ and coke $34 \mathrm{MJ}$. Sonication represents the low energy usage of about $0.9 \mathrm{MJ}$ during production of graphene ink. Miscellaneous (1.3 MJ) captures water and other raw materials which are used but not considered in the energy calculation.

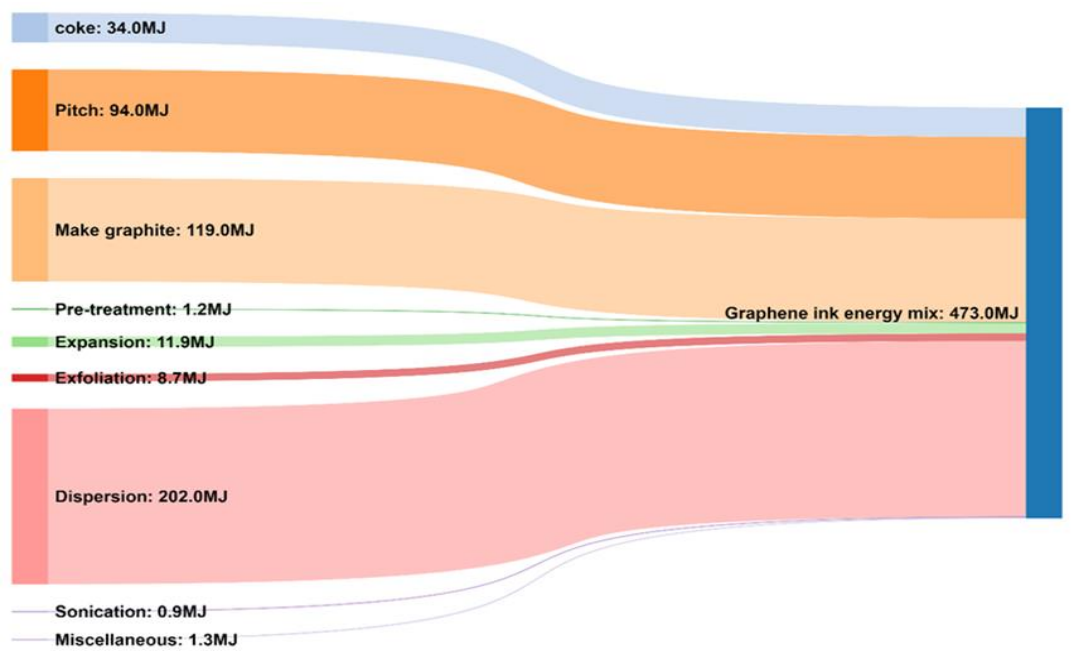

Fig. 7. Energy flow of processes/ materials to produce $3.2 \mathrm{~kg}$ of graphene ink. 


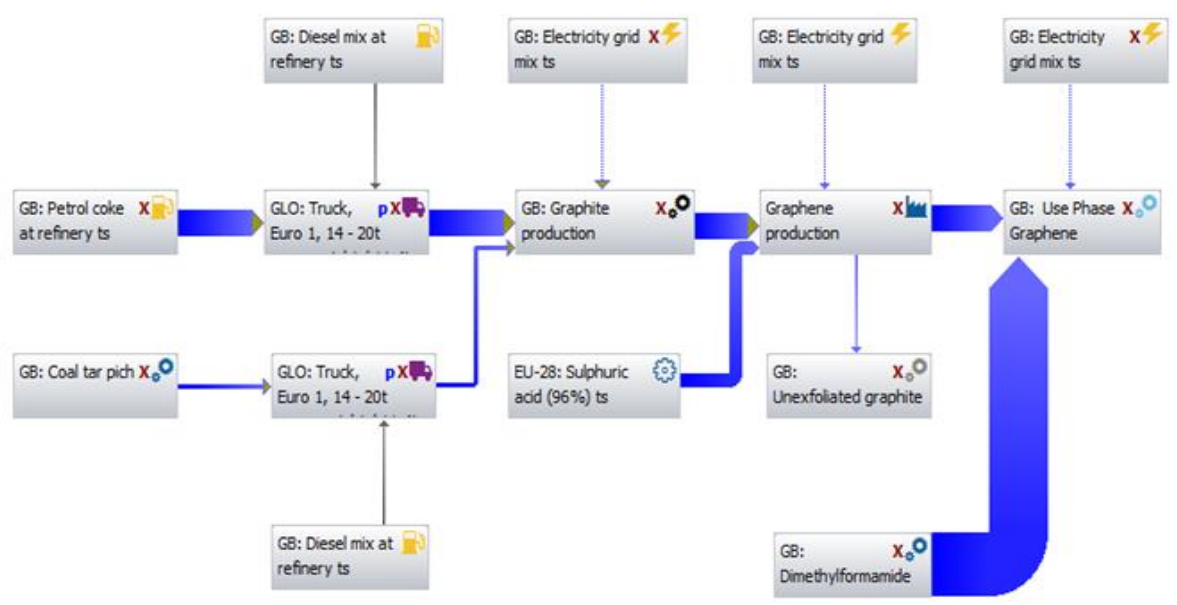

Fig. 8. LCA model of graphene capturing the cradle to gate approach

\subsection{Environmental Impact}

Production of carbon materials is known for its associated environmental impacts of which graphene is not an exception. Fig. 8 shows the LCA modelling of graphene using the 'cradle to gate' approach. The results obtained from the analysis of the modelling is shown in Fig. 9 and 10.

Fig. 9 shows that, graphene production leads to high emissions into the atmosphere including $\mathrm{CO}_{2}$ and dust particles. These are reported to be harmful to life and the environment at large. Furthermore, other emissions such as emissions into fresh water and sea water occurs during graphene production from its feedstock and these directly contribute to environmental burdens when graphene ink is produced in commercial scale. The reduction or prevention of these emissions requires more energy for their treatment which contribute directly to high energy consumption during graphene ink production.

However, Fig. 10 indicates that, serious non-lethal accident internally leads the health and safety result during graphene ink production. This implies that, the production of graphene ink has low risk of internal accident that may lead to loss of life.

\section{Conclusion}

The application of LCA to evaluate the energy utilization and environmental impact associated with graphene heating element has been fully assessed by capturing all relevant production processes, the quantity of raw materials and their associated energy requirements. The aim of this research has been achieved because, the process map, materials flow and energy flow represent the LCA model of graphene as heating element. The results that were obtained from the analysis can be summarised below. 
The result from the analysis shows that, for every $1 \mathrm{~kg}$ of graphene produced requires an embodied energy of 264-304 MJ.

Again, the result from the analysis indicates that, 454-492 MJ of energy is utilised for the production of $3.2 \mathrm{~kg}$ of graphene ink. This shows that, for every $1 \mathrm{~kg}$ of graphene ink produced, about 142-154 MJ of energy is consumed. Based on this, it can be deduced that, $1 \mathrm{~kg}$ of graphene produced, uses $52 \%$ more energy than the same quantity of $1 \mathrm{~kg}$ of graphene ink produced. It can be concluded that, there is possibility of reduction in energy consumption of graphene towards the use phase which must be confirmed by further investigations.

Furthermore, the result from the LCA of graphene modelling indicates that, emissions to air leads all emissions associated with graphene production. These emissions show the environmental impact associated with graphene ink production from its ore. Although these emissions are harmful to life, the safety result shows that there is no s erious internal accident associated with graphene ink production.

Diagram:LCA of graphene - Inputs/Outputs
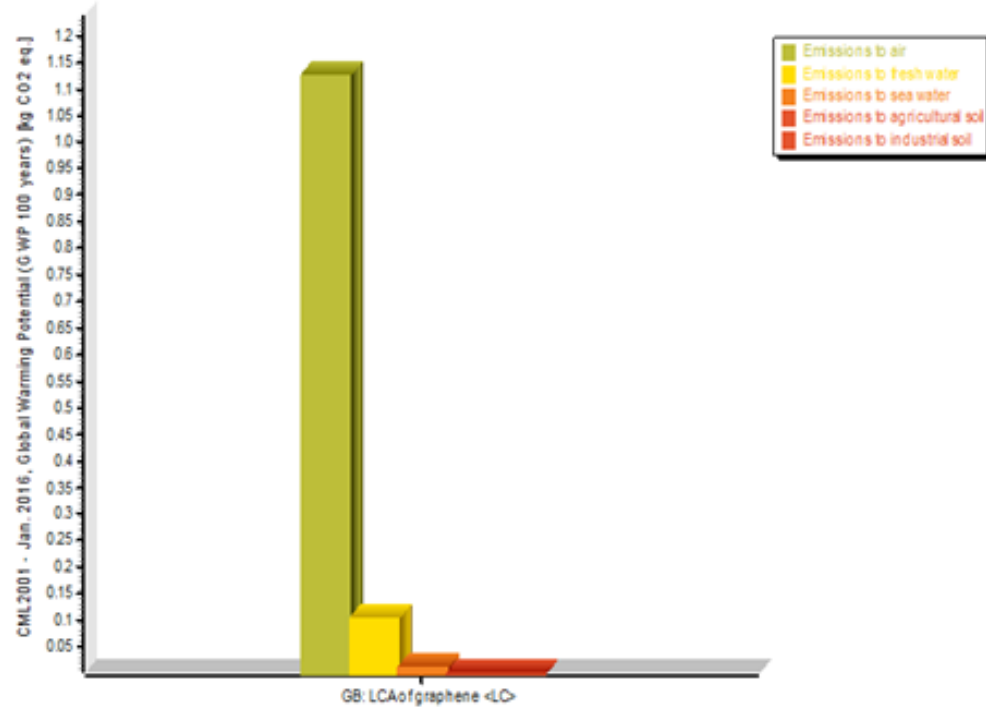

Fig. 9. Emissions associated with graphene ink production 
Diagram:LCA of graphene - Health and Safety (HSWT)

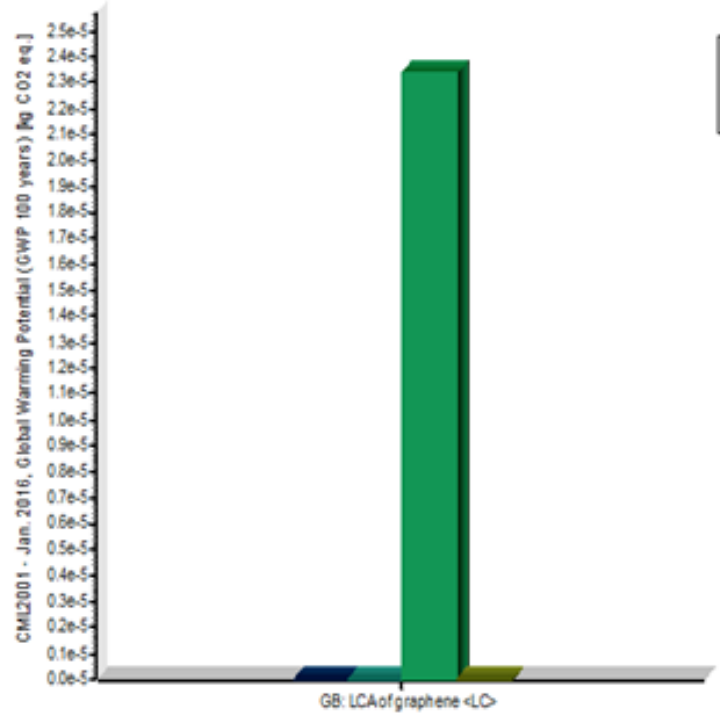

Fig. 10. Health and safety issues associated with graphene ink synthesis

\section{References}

1. Kim, J. H., Ahn, B. Du, Kim, C. H., Jeon, K. A., Kang, H. S., \& Lee, S. Y. (2008). Heat generation properties of $\mathrm{Ga}$ doped $\mathrm{ZnO}$ thin films prepared by rf-magnetron sputtering for transparent heaters. Thin Solid Films, 516(7), 1330-1333. https://doi.org/10.1016/j.tsf.2007.03.100

2. Kang, T. J., Kim, T., Seo, S. M., Park, Y. J., \& Kim, Y. H. (2011). Thickness-dependent thermal resistance of a transparent glass heater with a single-walled carbon nanotube coating. Carbon, 49(4), 1087-1093. https://doi.org/10.1016/j.carbon.2010.11.012

3. Sui, D., Huang, Y., Huang, L., Liang, J., Ma, Y., \& Chen, Y. (2011). Flexible and transparent electrothermal film heaters based on graphene materials. Small, 7(22), 3186-3192. https://doi.org/10.1002/smll.201101305

4. Yang, Y., et al., Graphene-based materials with tailored nanostructures for energy conversion and storage. Materials Science and Engineering: R: Reports, 2016. 102: p. 1-72.

5. Pathipati, S.R., et al., Graphene flakes at the $\mathrm{SiO} 2 /$ organic-semiconductor interface for high-mobility field-effect transistors. Organic Electronics, 2015. 27: p. 221-226.

6. $\mathrm{Li}, \mathrm{X}$., et al., In-situ polymerization of poly aniline on the surface of graphene oxide for high electrochemical capacitance. Thin Solid Films, 2015. 584(0): p. 348-352.

7. Ali, M.E.A., et al., Thin film composite membranes embedded with graphene oxide for water desalination. Desalination, 2016. 386: p.67-76 
8. Jiang, D.-e., V.R. Cooper, and S. Dai, Porous Graphene as the Ultimate Membrane for Gas Separation. Nano Letters, 2009. 9(12): p. 4019-4024

9. Geim, A. K., \& Novoselov, K. S. (2007). The rise of graphene. Nature Materials, 6(3), 183-191. DOI: $10.1038 / \mathrm{nmat} 1849$

10. Randall, J.F., Designing Indoor Solar Products - Photovoltaic Technologies for AES, John Wiley \& Sons.

11. Cossutta, M. (2016). Life cycle analysis of graphene in a supercapacitor application (Doctoral dissertation, University of Nottingham).

12. Balandin, A. A. Thermal properties of graphene and nanostructured carbon materials. Nature Mater. 10, 569-581 (2011)

13. Moser, J., Barreiro, A. \& Bachtold, A. Current-induced cleaning of graphene. Appl. Phy s. Lett. 91, 163513 (2007).

14. Balandin, A. A., Ghosh, S., Bao, W., Calizo, I., Teweldebrhan, D., Miao, F., \& Lau, C. N. (2008). Superior thermal conductivity of single-layer graphene. Nano letters, $8(3)$, 902-907

15. Yu, P., Lowe, S. E., Simon, G. P., \& Zhong, Y. L. (2015). Electrochemical exfoliation of graphite and production of functional graphene. Current Opinion in Colloid and Interface Science. https://doi.org/10.1016/j.cocis.2015.10.007.

16. Pierson, H. O. (1993). Handbook of carbon, graphite, diamond, and fullerenes: Properties, processing, and applications.

17. Müller, A., Kauranen, P., Von Ganski, A., \& Hell, B. (2006). Injection moulding of graphite composite bipolar plates. Journal of Power Sources, 154(2), 467-471. https://doi.org/10.1016/j.jpowsour.2005.10.096

18. Thinkstep Gabi database, reference year 2017

19. Coleman, J. N., Lotya, M., O’Neill, A., Bergin, S. D., King, P. J., Khan, U., ... \& Shvets, I. V. (2011). Two-dimensional nanosheets produced by liquid exfoliation of layered materials. Science, 331(6017), 568-571.

20. Morales GM, Schifani P, Ellis G, Ballesteros C, Martínez G, Barbero C, et al. Highquality few layer graphene produced by electrochemical intercalation and microwave-assisted expansion of graphite. Carbon 2011; 49:2809-16.

21. Zaier, M., Vidal, L., Hajjar-Garreau, S., \& Balan, L. (2017). Generating highly reflective and conductive metal layers through a light-assisted synthesis and assembling of silver nanoparticles in a polymer matrix. Scientific Reports, 7, 12410. http://doi.org/10.1038/s41598-017-12617-8.

22. Pilditch, R. L., Lizardi, I., Nelson, B. C., \& Johnson, M. M. (2012). Skin-safe conductive ink and method for application on the body. U.S. Patent Application No. 13/147,690.

23. Chen, Z., Ren, W., Gao, L., Liu, B., Pei, S., \& Cheng, H.-M. (2011). Three-dimensional flexible and conductive interconnected graphene networks grown by chemical vapour deposition. Nature Materials, 10, 424. Retrieved from http://dx.doi.org/10.1038/nmat3001

24. Chen, W. Li, S., Chen, C. and Yan, L. (2011), Self-Assembly and Embedding of Nanoparticles by In Situ Reduced Graphene for Preparation of a 3D Graphene/Nanoparticle Aerogel. Adv. Mater., 23: 5679-5683. doi:10.1002/adma.201102838.

25. Grisales, C., Herrera, N., \& Fajardo, F. (2016). Preparation of graphite conductive paint and its application to the construction of RC circuits on paper. Phy sics Education, 51(5). https://doi.org/10.1088/0031-9120/51/5/055011. 
26. Murray-Smith R 2014 Making inks and paints www.youtube.com/watch?v=ot9gz-bAIss. Accessed 4/07/2018

27. Parvez, K., Wu, Z. S., Li, R., Liu, X., Graf, R., Feng, X., \& Müllen, K. (2014). Exfoliation of graphite into graphene in aqueous solutions of inorganic salts. Journal of the American Chemical Society, 136(16), 6083-6091. https://doi.org/10.1021/ja5017156

28. Su, C. Y., Lu, A. Y., Xu, Y., Chen, F. R., Khlobystov, A. N., \& Li, L. J. (2011). Highquality thin graphene films from fast electrochemical exfoliation. ACS Nano, 5(3), 23322339. https://doi.org/10.1021/nn200025p

29. Monopoli, M. P., Bombelli, F. B., \& Dawson, K. A. (2011). Nanobiotechnology: nanoparticle coronas take shape. Nature nanotechnology, 6(1), 11.

30. Krug, H. F., \& Wick, P. (2011). Nanotoxicology: an interdisciplinary challenge. Angewandte Chemie International Edition, 50(6), 1260-1278.

31. Sanchez, V. C., Jachak, A., Hurt, R. H., \& Kane, A. B. (2011). Biological interactions of graphene-family nanomaterials: an interdisciplinary review. Chemical research in toxicology, 25(1), 15-34.

32. Feng, L., \& Liu, Z. (2011). Graphene in biomedicine: opportunities and challenges. Nanomedicine, 6(2), 317-324

33. Bussy, C., Ali-Boucetta, H., \& Kostarelos, K. (2012). Safety considerations for graphene: lessons learnt from carbon nanotubes. Accounts of chemical research, 46(3), 692-701.

34. Jastrzębska, A. M., Kurtycz, P., \& Olszyna, A. R. (2012). Recent advances in graphene family materials toxicity investigations. Journal of Nanoparticle Research, 14(12), 1320.

35. Hu, X., \& Zhou, Q. (2013). Health and ecosystem risks of graphene. Chemical reviews, 113(5), 3815-3835.

36. Bianco, A. (2013). Graphene: safe or toxic? The two faces of the medal. Angewandte Chemie International Edition, 52(19), 4986-4997.

37. CES EduPack database reference year 2017

38. Wang J, et al. (2011) High-yield synthesis of few-layer graphene flakes through electrochemical expansion of graphite in propylene carbonate electroly te

39. Adeniran, J. A., Yusuf, R. O., \& Adetoro, M. A. (2017). Life cycle engineering case study: Sulphuric acid production. Journal of Engineering and Technology (JET), 8(2).

40. Zhamu, A.; Jang, B. Z. Mass Production of Pristine Nano Graphene Materials, US8226801B2; Nanotek Instruments Inc.: United States 2012

41. Capello, C., Fischer, U., \& Hungerbühler, K. (2007). What is a green solvent? A comprehensive framework for the environmental assessment of solvents. Green Chemistry, 9(9), 927-934. 
$2019-12-31$

Life cycle assessment of graphene as heating element

\author{
Ampah, Araba Darkoa
}

Springer

Ampah AD, Pagone E, Salonitis K. (2019) Life cycle assessment of graphene as heating element. In: 6th International Conference on Sustainable Design and Manufacturing,

(KES-SDM-2019), 4-5 July 2019, Budapest

https://doi.org/10.1007/978-981-13-9271-9_24

Downloaded from Cranfield Library Services E-Repository 